\title{
Studies on the Determination of Formaldehyde in Squid and Bummalo
}

\author{
Xuan Zhang ${ }^{1}$, Xiao Sheng Shen ${ }^{1}$, Yun Hua Hui ${ }^{1}$, Cong Kong ${ }^{1}$, Yuan Wang ${ }^{1}$, Bing Feng ${ }^{1}$,You Qiong CAI ${ }^{1}$, Dong Mei \\ Huang $^{1, *}$ \\ ${ }^{1}$ East China Sea Fishery Research Institute, Chinese Academy of Fishery Sciences, 200090, Shanghai, China \\ Laboratory of Quality \& Safety Risk Assessment for Aquatic Products (Shanghai), Ministry of Agriculture
}

\begin{abstract}
The paper tends to study the determination of formaldehyde in squid and bummalo by HPLC. The calibration curve in the $0.5-50.0$ $\mu \mathrm{g} / \mathrm{mL}$ range was obtained and correlation coefficient was 0.9993 . The detection limit was $5 \mathrm{mg} / \mathrm{kg}$. Endogenous formaldehyde in bummalo and squid as well as the change rule of formaldehyde under the frozen storage condition was assessed. Results showed that the formaldehyde content in bummalo was higher than the squid. Under the same storage conditions, formaldehyde content both in bummalo and squid were significantly increased in pace with frozen storage time. Therefore, inspection agencies should indicate the sampling time and testing time, when they detect the formaldehyde content in aquatic products.
\end{abstract}

\section{Introduction}

Squid and bummalo are good sources of protein, vitamin and lipid and are abundant with high nutritional value. Generally, aquatic products are frozen after capture and are sold in frozen or processing state. Recently, people are paying more attention to formaldehyde in aquatic products. As a toxic substance, formaldehyde (FA) is easy to react with nucleophilic material, causing DNA damage. In 2004, FA was categorized in Group I as 'carcinogenic to humans' by the International Agency for Research on Cancer (IARC) [1].

The United States Environmental Protection Agency recommended daily intake of $\mathrm{FA}$ as no more than $0.2 \mathrm{mg} / \mathrm{kg}$ of the body weight while WHO set it as $0.15 \mathrm{mg} / \mathrm{kg}$ of the body weight. In 1985, Italian health departments set limit of FA in cod and shellfish aquatic products respectively $60 \mathrm{mg} / \mathrm{kg}$ and $10 \mathrm{mg} / \mathrm{kg}$ [2], while Chinese ministry of agriculture, set it to $10 \mathrm{mg} / \mathrm{kg}$ in aquatic products since 2002 [3]. IbenEllegaad reported that FA present three states in aquatic products according to different combinations of FA with protein: one is free state, the other one is free and reversibly bound state which is available only through steam distillation under the sulfuric acid or phosphoric acid solution ( $1 \%-40 \%)$, the third one is irreversible combined state [4]. This study focused on detecting only free FA, because free FA is reported to be toxicological interest and that it should be measured [5].

Methods of the detection of FA in aquatic products mainly include spectrophotometry [6, 7], high performance liquid chromatography (HPLC) [8-10] and gas chromatography (GC) [11]. Spectrophotometry has some advantages of simple equipment, low cost and fast operation, and disadvantages of poor accuracy, worse sensitivity, and easily influenced by complex food matrix. Chromatography with high sensitivity, stable derivatives, strong esistance against interference, high recovery rate, convenient and rapid operation is widely used for detecting FA in aquatic products. This paper selects the HPLC method and developed it to determine the FA content in squid and bummalo.

This paper chose squid and bummalo which were obtained both from market and marine as study objects.
By studying background concentration of FA in fish muscle, we preliminary studied the mechanism of FA, researched concentration changing of FA with the time under frozen condition, the aim of the study was to provide guidance for processing and storage of squid and bummalo.

\section{Experimental section}

\subsection{Chemicals and equipment}

Ultrapure water was prepared by Millipore water purification system (Millipore, the USA); Acetonitrile was chromatographic pure (Baker, the USA), 2, 4-dinitrophenylhydrazine (DNPH) and the rest of the reagents were analytically pure; Formaldehyde standard: $10 \mathrm{mg} / \mathrm{mL}, 2 \mathrm{~mL}$ (Aladdin, Shanghai).

Formaldehyde standard solution $(200 \mu \mathrm{g} / \mathrm{mL}): 2$ $\mathrm{mL}$ of FA standard was dissolved into $100 \mathrm{~mL}$ ultrapure water, and the standard intermediate liquid could be used for six months saved at $4{ }^{\circ} \mathrm{C}$.

The high-performance liquid chromatography (Agilent Technologies 1100 HPLC, the USA) consisted of a pump, a VU detect, a column chamber, and an Agilent ChemStation for LC system. The HPLC column was a Hypersil ODS-C18, 4.6mm $\times 250 \mathrm{~mm}, 5 \mu \mathrm{m}$. The sample volume was set at $20 \mu 1$, the absorb wavelength of detector was set at $365 \mathrm{~nm}$, the column temperature was set at $40{ }^{\circ} \mathrm{C}$. The mobile phase was methanol-water $(70: 30, \mathrm{v} / \mathrm{v})$ with a flow rate of $0.9 \mathrm{~mL} / \mathrm{min}$. The peak area was used for quantitative calculation of formaldehyde.

\subsection{Sample derivatization and extraction}

Squid and bummalo as samples of FA concentration study were bought from Shanghai aquatic product market, while samples of growth and decline law study were bought from the fishing boat return, all samples were frozen in lab. We also found that basically all kinds of aquatic product market in Shanghai sold ice fresh squid and bummalo as a whole (including internal organs), for this reason, samples were not eviscerated in this paper. 
Made the frozen fish thawing at room temperature, then filleted, minced and homogenized the muscle part.

For determining FA content, mixed $(2+0.02) \mathrm{g}$ homogenized sample and $20.0 \mathrm{~L}$ derivative liquid in 50 $\mathrm{mL}$ polypropylene centrifuge tube, tighten the plug, and then blent through vortex device, then put in Waterbathing Constant Temperature Vibrator at $60{ }^{\circ} \mathrm{C}$, $150 \mathrm{r} / \mathrm{min}$ for $1 \mathrm{~h}$, took out and blent every $20 \mathrm{~min}$ in the whole process. The extracting solution was centrifuged at $4000 \mathrm{r} / \mathrm{min}$ for $5 \mathrm{~min}$. The mixture was filtered through a 0.45 um HV filter before injection. For each sample three replicates were analyzed. Results were expressed as mg of $\mathrm{FA} / \mathrm{kg}$.

\subsection{Calibration curve}

Respectively took $0.025,0.05,0.25,0.5,1.0,2.5 \mathrm{~mL}$ FA standard solution $(200 \mu \mathrm{g} / \mathrm{mL})$ into $50 \mathrm{~mL}$ polypropylene centrifuge tube, added buffer solution to $5 \mathrm{~mL}$, and derivative liquid to $10.0 \mathrm{~mL}$, hence FA standard solution was respectively diluted into $0.5,1.0,5.0,10.0,20.0,50.0$ $\mu \mathrm{g} / \mathrm{mL}$ as FA work solution. The FA work solution was derivatised and extracted according to described procedures. Three injections of each standard solution were made and the peak area was the corresponding FA content to obtain the calibration curve.

\section{Results and discussion}

\subsection{Liquid chromatographic analysis}

Fig. 1 showed chromatogram of FA word standard solution by HPLC. Two main chromatographic peaks were found in the $3.76 \mathrm{~min}$ and $5.16 \mathrm{~min}$ respectively. The peak in 3.76 min was residual DNPH, the other peak in $5.16 \mathrm{~min}$ was considered to be a derivative of HCHODNPH in the FA work standard solution. The calibration curve in the $0.5-50.0 \mu \mathrm{g} / \mathrm{mL}$ range was obtained and correlation coefficient was 0.9993 . The detection limit was $5 \mathrm{mg} / \mathrm{kg}$ in squid sample. The average recoveries of this method were in the range of $70-110 \%$. As general results, the method indicated good linear relationship, good selectivity and accuracy with simple procedure in the determination of FA.

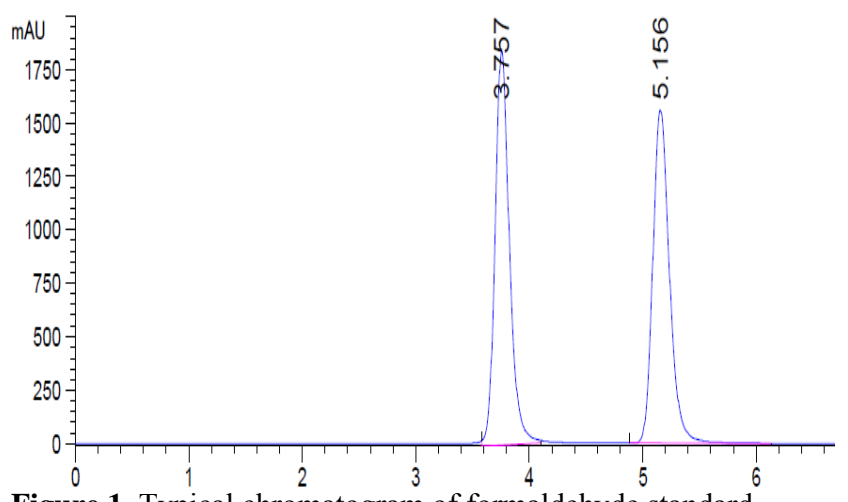

Figure 1. Typical chromatogram of formaldehyde standard solution. Peak identified as: (1) DNPH; (2) HCHO-DNPH.

\subsection{FA concentration in squid and bummalo}

Fig. 2 showed FA concentrations in squid and bummalo which were bought from aquatic product market. Basically, the FA content of squid fish is markedly lower than bummalo, FA content of squid was in the range of $15.1-146 \mathrm{mg} / \mathrm{kg}$, average $42.1 \mathrm{mg} / \mathrm{kg}$, and $40 \%$ was lower than LOQ, while bummalo was in the range of 17.5-374 $\mathrm{mg} / \mathrm{kg}$, average $164 \mathrm{mg} / \mathrm{kg}$, four times as much as the squid. FA content exceeding $60 \mathrm{mg} / \mathrm{kg}$ in bummalo accounted for $70 \%$, while only $1 \%$ in squid, which far exceeded the FA limit by Ministry of Agriculture in China. The results were consistent with existing literature literature $[12,13]$. However, there is no specific explanation of why FA concentration in bummalo is significantly higher than the squid. This article studied related domestic and foreign literature and found that, Trimethylamine oxide demethylation enzyme (TMAOase) widely exists in various aquatic varieties, it is generally believed trimethylamine oxide (TMAO) could resolve into FA and dimethylamine under enzymolysis condition of TMAOase [14]. The production of FA was influenced by enzymatic activity and cofactor system (such as Fe2+, ascorbic acid, cysteine, etc.). Some research showed that TMAOase activities behaved large variations between species as well as between individuals and organs, and that resulted in large variation in the rate of FA accumulation $[15,16]$, furthermore enzyme activity was affected by storage temperature [17]. However, the specific process of why FA content was far different between squid and bummalo remained further research.

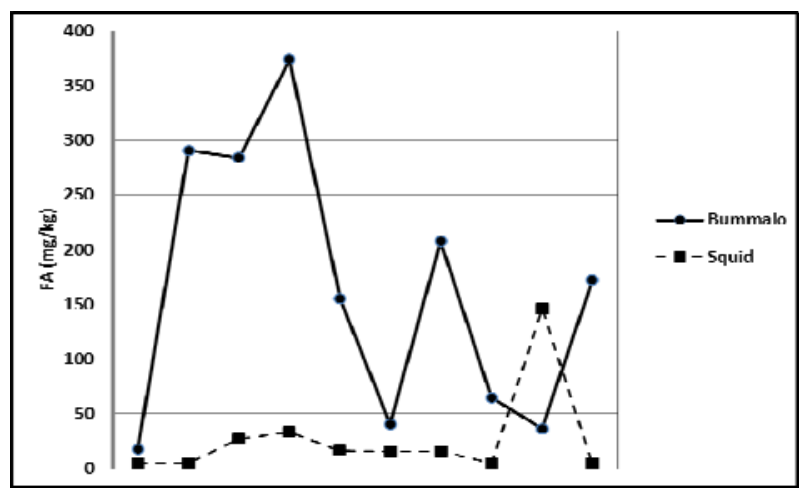

Figure 2.Comparison chart of formaldehyde in squid and bummalo bought from Shanghai market.

\subsection{The change trend of FA under the frozen storage condition}

This study also discussed the change trend of FA under the frozen storage condition in squid and bummalo, all samples were gotten from the fishing boat return, so the whole process was without artificially added FA. The change of FA content in bumbalo and squid was showed in Table 1. After 20 days frozen, the FA content of squid was markedly lower than the bumbalo with range 15.2$62.7 \mathrm{mg} / \mathrm{kg}$, average $33.0 \mathrm{mg} / \mathrm{kg}$, while bummalo was range $15.2-62.7 \mathrm{mg} / \mathrm{kg}$, average $105 \mathrm{mg} / \mathrm{kg}$, three times higher than squid. In other word, the concentration of FA in bumbalo was significantly higher than squid under the same storage condition. High levels of the enzyme could 
be the main reason as for the FA content in bummalo was significantly higher than in the squid. Harada reported that not all varieties of squid could happen enzymatic hydrolysis reaction to release FA [18], which explained the four samples in the frozen had low levels of FA content $(<5 \mathrm{mg} / \mathrm{kg})$ for 20 days and 3 months. Frozen after 3 months, FA content in squid rose to range 109-596 $\mathrm{mg} / \mathrm{kg}$, average $226 \mathrm{mg} / \mathrm{kg}$, rising at a rate of $649 \%$, and in bummalo rose to range $383-886 \mathrm{mg} / \mathrm{kg}$, average 544 $\mathrm{mg} / \mathrm{kg}$, rising at a rate of $523 \%$. FA content in both squid and bummalo increased by about $500 \%$, under the same storage condition, so the conclusion was that FA concentration increased with the frozen storage time. Therefore, when it comes to the determination of FA

content in aquatic products, the sampling time and testing time should be given out.

\section{Conclusions}

Both bumbalo and squid produced endogenous formaldehyde regardless they were got from aquatic product market or the fishing boat. FA content in bumbalo was apparently higher than that in squid. The formaldehyde content in both bumbalo and squid significantly increased with the extension of frozen storage time under the same storage conditions. When the inspection agencies detect the formaldehyde content in aquatic products, should indicate the sampling time and testing time.

Table 1. The change of formaldehyde content in bumbalo and squid

\begin{tabular}{ccccc}
\hline FA[mg/kg] & Frozen 20 days & Frozen 3 months & Rising rate [\%] & Sample state \\
\hline Squid & 34.1 & 186 & 545 & 356 \\
Squid & 33.7 & 120 & 717 \\
Squid & 15.2 & 109 & 714 \\
Squid & 27.3 & 195 & 951 \\
Squid & 62.7 & 596 & 609 \\
Squid & 24.8 & 151 & $<5$ & Normal odor and Tight meat \\
Squid & $<5$ & $<5$ & $<5$ & $<5$ \\
Squid & $<5$ & $<5$ & $<5$ & \\
Squid & $<5$ & $<5$ & 418 & \\
Squid & $<5$ & $<5$ & 600 & \\
Bumbalo & 114 & 476 & 458 \\
Bumbalo & 63.8 & 383 & 558 \\
Bumbalo & 95.4 & 437 & 563 \\
Bumbalo & 100 & 558 & 544 & \\
Bumbalo & 92.9 & 523 & \\
Bumbalo & 163 & 886 & & \\
\hline
\end{tabular}

\section{Acknowledgements}

This study was supported by the research grant (No.2015T08) supported by the East China Sea FisheriesResearch Institute, Chinese Academy of Fishery Sciences.

\section{References}

[1] IARC. International Agency for Research on Cancer; Lyon, France, 88 (2004)

[2] MINSAN-telegram no. 703/3266/6/1377 08.11.1985

[3] China's Ministry of Agriculture. NY5172-2002

[4] Iben, E.B., Anal. Chem. Acta, J. 320, 155-164 (1996).

[5] Bechmann IE, Lebensm Wiss Technol. J. 31, 449453 (1998)

[6] H. Qiang, H. X. Zhu, R.H. Zhu, S. Li, R.Q. Nie., Food Sci. J. 30, 371-374 (2009)

[7] L.Z. Zhang, Z. R. Zhou, Q .Wang, S. Y. Zhang., Food Res. Dev. J. 31,121-124 (2010)

[8] M. S. Joseph, C. A. Wendy, H. Andrea, B. T. Sherri, L. Jack, T. Terri, M. Mark., Food Addit. Contam. A. J. 32, 657-664 (2015)
[9] D.H. Jiang., In New Technology of Agricultural Engineering (ICAE); 2011 International Conference, (IEEE Press: Zibo, 2011; pp 802-805)

[10] L. G. Chen, H. Y. Jin, H. Y. Xu, L. Sun, A.M. Yu, H. Q. Zhang, L.A. Ding., Agr. Food Chem. J. 57, 39893994 (2009)

[11] Y. J. Ma, C. Zhao, Y.-S. Zhan, J.-B. Li, Z.M. Zhang, G.-K. Li., Sep. Sci. J. 38, 1388-1393 (2015)

[12]F. Bianchi, M. Careri, M. Musci, A. Mangia., Food Chem. J. 100, 1049-1053 (2007)

[13] J.R. Li, J.L. Zhu, L.F. Ye., Asia Pac. Clin. Nutr. J. 16, 127-30 (2007)

[14]X.Y. Fu, C.H. Xue, B.C. Miao, J.N. Liang, Z.J. Li, F.X. Cui., Agr. Food Chem. J. 54, 968-972 (2006)

[15] M. R. Mansilla, C. G, Sotelo, R.I. Pérez-Martin., Food Sci. J. 67, 3242-3251 (2006)

[16] M. K. Nielsen, B. M. Jørgensen., Agr. Food Chem. J. 52, 3814-3822 (2004)

[17]B. Q. Phillippy, H. O. Hultin., Food Biochem. J. 17, 235-250 (1993)

[18]K. Harada., Shimonoseki Univ. Fish. J. 23, 163-241 (1975) 